\title{
Application of Shell Element in Temperature Field Predication of Wind Turbine Blade
}

\author{
Tianyu Ning ${ }^{1,2}$, Qixing $\mathrm{Liu}^{2}$, Jiling $\mathrm{Bu}^{2, *}$, Yong Zheng ${ }^{2}$, Changda $\mathrm{Li}^{2}$ and Wentao Yang ${ }^{2}$ \\ ${ }^{1}$ Zhuzhou Times New Material Technology Co., Ltd., Zhuzhou, Hunan, 412007, China \\ ${ }^{2}$ Department of Mechanical Engineering, Xiangtan University, Xiangtan, Hunan, 411105, China
}

\begin{abstract}
For anti-icing wind turbine blades, hot air heating method is widely adopted due to its various advantages such as easy maintenance. This article proposes a temperature field predication method for wind tribune blade based on ANSYS SHELL131 shell element. Firstly, by building a solid model, it verifies the feasibility of merging plies of wind turbine blades of the same material. Then it uses an anti-icing apparatus with hot air heating to measure the temperature field data by experiment. Based on characteristics of SHELL131 element, it merges and simplifies plies of an actual wind turbine blade to obtain an appropriate shell element model. Finally, after computing the temperature field of the whole blade by ANSYS, it verifies the feasibility of this method by showing good agreement between the simulation and the experimental results. In practice, this method can be applied to temperature field computations for varies types of wind turbine blades and other laminated structures, and it can provide reliable theoretic guidance for heat transfer analysis of wind turbine blade and research on anti-icing equipment of blades.
\end{abstract}

Keywords: Shell element, anti-icing technology, wind turbine blade, temperature field.

\section{INTRODUCTION}

Currently, wind energy projects are mainly located in China's northern and south-eastern coastal areas. In recent years, it witnessed a rapid development of wind energy market in the southern areas. Among the approved wind energy projects of China's 12th Five Year Plan, there is a dramatic increase in the southern areas. However, during the icy period lasting for several months in the winter of the southern areas, wind turbine blades will be frozen, reducing the productivity [1-2]. Therefore, it urgently requires a new type of anti-icing blade.

As one of the most common anti-icing methods, the hot air heating method [3-6] heats the air by heating devices and then transmits the hot air to the inner surface of blade through air blower equipment and airflow pipeline to realize deicing and anti-icing. The finite element method used to predict the temperature field can greatly decrease ground tests and provide guidance for anti-icing system optimization.

Currently, there are quite a few researches on predicting temperature field of wind turbine blades. As a fiberreinforced composite material, wind turbine blade has an uneven distribution of number of plies and types of glass fiber fabric at different areas. At some areas, there is even sandwich structure with Balsa, PVC foam core material. Based on the types of glass fiber fabric, core material and

*Address correspondence to these authors at the Department of Mechanical Engineering, Xiangtan University, Xiangtan, Hunan, 411105, China; Tel: +86 0086-731-28491665; E-mail: bujiling@csrzic.com number of plies, one blade can be divided into hundreds of areas. If a solid element is used for the solid model, there will exist several problems such as difficulty of building a solid model, incapacity to partition blade properly, too many equivalent thermophysical parameters for measurement, poor applicability of equivalent thermophysical properties to different blade types and insufficient method portability.

To solve the above problems, this article, based on ANSYS finite element software, applies shell element (SHELL131) to compute the temperature field of the blade. In terms of the blade model, the shell elements of wind turbine blade can be used based on FOCUS software. The main advantage is that it can solve the problems like difficulty of building solid models and capturing equivalent thermophysical parameters of composite material. In this way, it discovers a new way for heat transfer analysis of composite material with laminated structure like wind turbine blade.

\section{TEMPERATURE FIELD PREDICATION METHOD FOR WIND TURBINE BLADE}

\subsection{Characteristics of SHELL131 Element}

SHELL131 element of ANSYS is a 4-node 3D layered shell element with in-plane and through-thickness thermal conduction capability, the element has four nodes with up to 32 temperature degrees of freedom [7-8]. The geometry of SHELL131 is shown in Fig. (1). It should be noted that for SHELL131 element the maximum number of plies is 30 . Besides this, the property settings of SHELL131 elements are different from those of other shell elements. With SHELL131 element, each component of the model must be assigned a corresponding element type. For successful com- 
putation, the number of plies for element property settings must be the same as the number of plies after merging at each area. Therefore, according to the specific ply structure of the wind turbine blade, the settings of SHELL131 elements in terms of number of plies should be the same as number of different types of ply areas. In this way, it corresponds the elements to the section properties at each area.

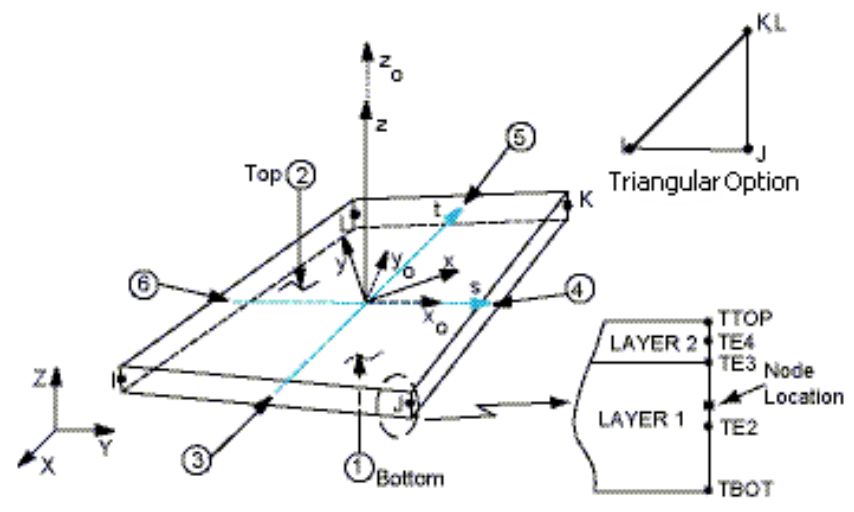

Fig. (1). Geometry of SHELL131 element.

\subsection{Temperature Field Analysis Method}

The actual wind turbine blade generally consists of glass fabric, Balsa, PVC foam material which is layered according to certain sequences, and then it is made by vacuum infusion with epoxy resin. The number of plies for glass fabric exceeds 30 in most areas, for some areas the number can reach one hundred. In order to simplify the computation and meet the computation requirements of ANSYS, the number of plies should be reduced within 30 through simplification.

After analyzing the structure of the actual blade, plies of the same material will be merged. Then it builds the finite element analysis model through shell elements with FOCUS software. Actually, pre-processing is mainly performed in Hypermesh, including meshing, material assignment, element type switch and element property settings. Load and boundary conditions are set in ANSYS. The flow chart indicating the whole sequence is shown in Fig. (2).

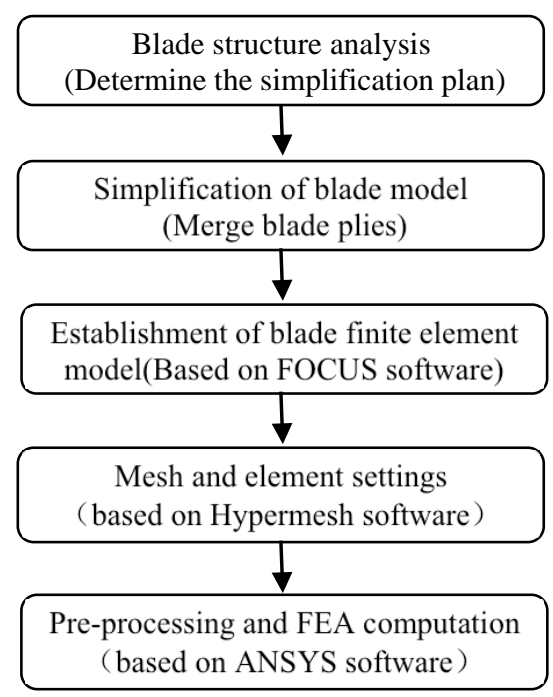

Fig. (2). Temperature field analysis flow chart of wind turbine blades.

\subsection{Theories of Transient Heat Transfer}

In hot air heating method, deicing equipment is generally installed on the root section of the blade, and hot air is transmitted to the blade inside by air blower fans and airflow pipelines for deicing. During the whole process, the heat transfer condition of blade keeps changing, which refers to a transient process. The general form of differential equation for 3-D unsteady heat conduction process is shown as (1). The heat transfer between the blade external surface and air is computed through the third type boundary condition, which refers to heat convection. The temperature load on the blade inner surface requires the temperature data from experiment, so it applies the first type boundary condition [9] to the temperature field of blade inner surface.

$$
\frac{\partial T}{\partial \tau}=a\left(\frac{\partial^{2} T}{\partial x^{2}}+\frac{\partial^{2} T}{\partial y^{2}}+\frac{\partial^{2} T}{\partial z^{2}}\right)+\frac{\Phi}{\rho c}
$$

The first type boundary condition is displayed as (2)

$$
q=-k \frac{\partial T}{\partial n}
$$

The third type boundary condition is displayed as (3)

$$
q=h\left(T_{w}-T_{f}\right)
$$

Where $\mathrm{q}$ is heat flux $(\mathrm{W} / \mathrm{m} 2), \rho$ is material density $(\mathrm{kg} / \mathrm{m} 3)$, $\mathrm{C}$ is specific heat capacity of the material $\left(\mathrm{J} / \mathrm{kg} \cdot{ }^{\circ} \mathrm{C}\right), \mathrm{k}$ is thermal conductivity $\left(\mathrm{W} / \mathrm{m} \cdot{ }^{\circ} \mathrm{C}\right), \mathrm{h}$ is heat transfer coefficient $\left(\mathrm{W} /\left(\mathrm{m} 2 \cdot{ }^{\circ} \mathrm{C}\right)\right), \Phi$ is internal energy per unit volume $\left(\mathrm{J} / \mathrm{m}^{3}\right)$, $\mathrm{Tw}$ is temperature of the blade inner surface $\left({ }^{\circ} \mathrm{C}\right)$, Tf is ambient temperature $\left({ }^{\circ} \mathrm{C}\right)$.

\subsection{Ply Merging Method and Verification}

For the ply of the same material, ply merging method is applied to simplify the model and meet the computation requirements of ANSYS. In order to verify its feasibility, three simple ply models are demonstrated here with its individual meshing as shown in Fig. (3). All the three models use SHELL131 elements, the second and third ply structure are obtained from the first by merging plies of glass fiber fabric. Details regarding the specific ply information are shown in Table 1.

Normally, when the temperature range related to computation is about 20 Celsius degrees, the material thermophysical parameters changes little within the temperature range [10]. Here, the temperature range related to computation is not large, so it assumes the material thermophysical parameters are constant regardless of the temperature change. Since the temperature field of the blade outer surface is the interest of computation, the main factor of the thermal conductivity will be in the through-thickness direction. Therefore, here it assumes that the material is isotropic with a thermal conductivity of the value in radial direction. Details regarding the material parameters are shown in Table 2.

The same boundary condition is applied to the three ply structures. The first type boundary condition is applied to the lower surface with a constant temperature of $45^{\circ} \mathrm{C}$. The third type boundary condition is applied to the upper surface, 

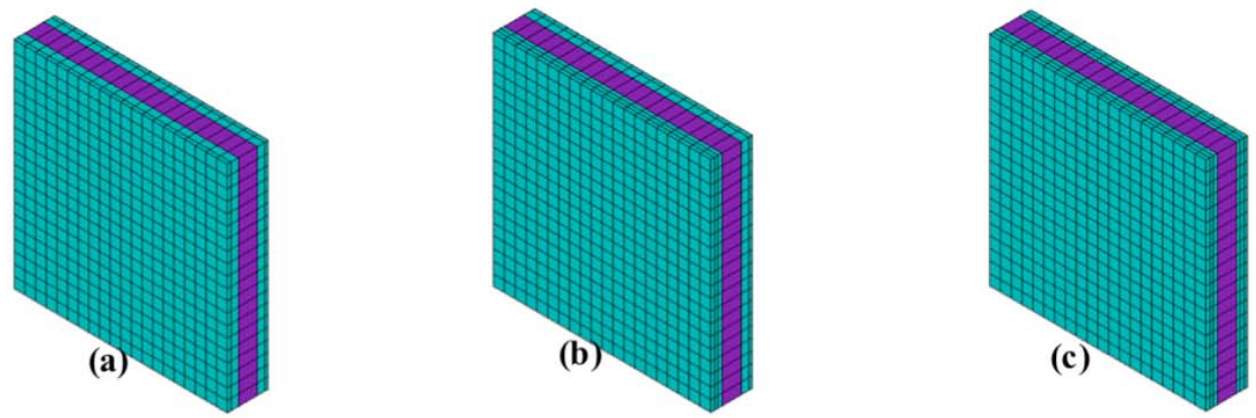

Fig. (3). Computation models of three ply structures, (a) the first ply structure, (b) the second ply structure, (c) the third ply structure.

Table 1. Three ply structures.

\begin{tabular}{|c|c|c|c|c|c|c|}
\hline \multirow[b]{2}{*}{ Ply sequence } & \multicolumn{2}{|c|}{ 1st ply structure } & \multicolumn{2}{|c|}{ 2nd ply structure } & \multicolumn{2}{|c|}{ 3rd ply structure } \\
\hline & $\begin{array}{l}\text { Thick } \\
(\mathrm{mm})\end{array}$ & Material & $\begin{array}{l}\text { Thick } \\
(\mathrm{mm})\end{array}$ & Material & $\begin{array}{l}\text { Thick } \\
(\mathrm{mm})\end{array}$ & Material \\
\hline 1 st ply & 1.7 & glass fabric & 1.7 & glass fabric & 1.7 & glass fabric \\
\hline 2nd ply & 1.7 & glass fabric & 3.4 & glass fabric & 3.4 & glass fabric \\
\hline 3rd ply & 1.7 & glass fabric & 9.0 & Balsa & 9.0 & Balsa \\
\hline 4th ply & 9.0 & Balsa & 1.7 & glass fabric & 3.4 & glass fabric \\
\hline 5th ply & 1.7 & glass fabric & 1.7 & glass fabric & 1.7 & glass fabric \\
\hline 6th ply & 1.7 & glass fabric & 1.7 & glass fabric & --- & --- \\
\hline 7th ply & 1.7 & glass fabric & --- & --- & --- & --- \\
\hline
\end{tabular}

Table 2. Thermophysical parameter of the materials.

\begin{tabular}{|c|c|c|c|c|}
\hline Thermal Property & Unit & FRP & Balsa & PVC \\
\hline \hline Thermal conductivity & $\mathrm{W} / \mathrm{m} \cdot{ }^{\circ} \mathrm{C}$ & 0.300 & 0.064 & 0.031 \\
\hline Density & $\mathrm{kg} / \mathrm{m}^{3}$ & 1906 & 150 & 60 \\
\hline Specific heat capacity & $\mathrm{J} / \mathrm{kg} \cdot{ }^{\circ} \mathrm{C}$ & 1100 & 1000 & 1200 \\
\hline
\end{tabular}

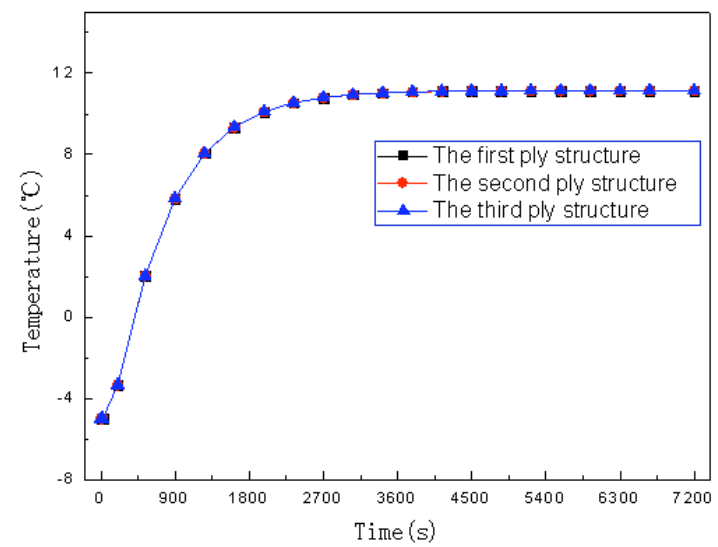

Fig. (4). Three curves of surface temperature of three ply structures varying with time.

which refers to a heat transfer coefficient of $\mathrm{h}=12.5 \mathrm{~W} /(\mathrm{m} 2$. ${ }^{\circ} \mathrm{C}$ ) in heat convection boundary condition. Both the ambient temperature and initial temperature are set as $-5^{\circ} \mathrm{C}$. After processing the three models with ANSYS respectively, the three curves of upper surface temperature versus time are shown in Fig. (4).

From the above figure, it can be seen that for computing ply structures with SHELL131 elements in ANSYS, if plies of the same material are merged and the total thickness after merging is kept the same, it will not affect the final results. In this way, by merging plies of the same material in local areas of the blade, the numbers of plies for the whole blade can be kept within 30 .

\section{TEMPERATURE FIELD EXPERIMENT OF WIND TURBINE BLADE}

\subsection{Equipment}

The hot air anti-icing system here mainly consists of control devices, heating devices, blower fans and airflow pipelines. As shown in Fig. (5), the heating devices, blower fans 

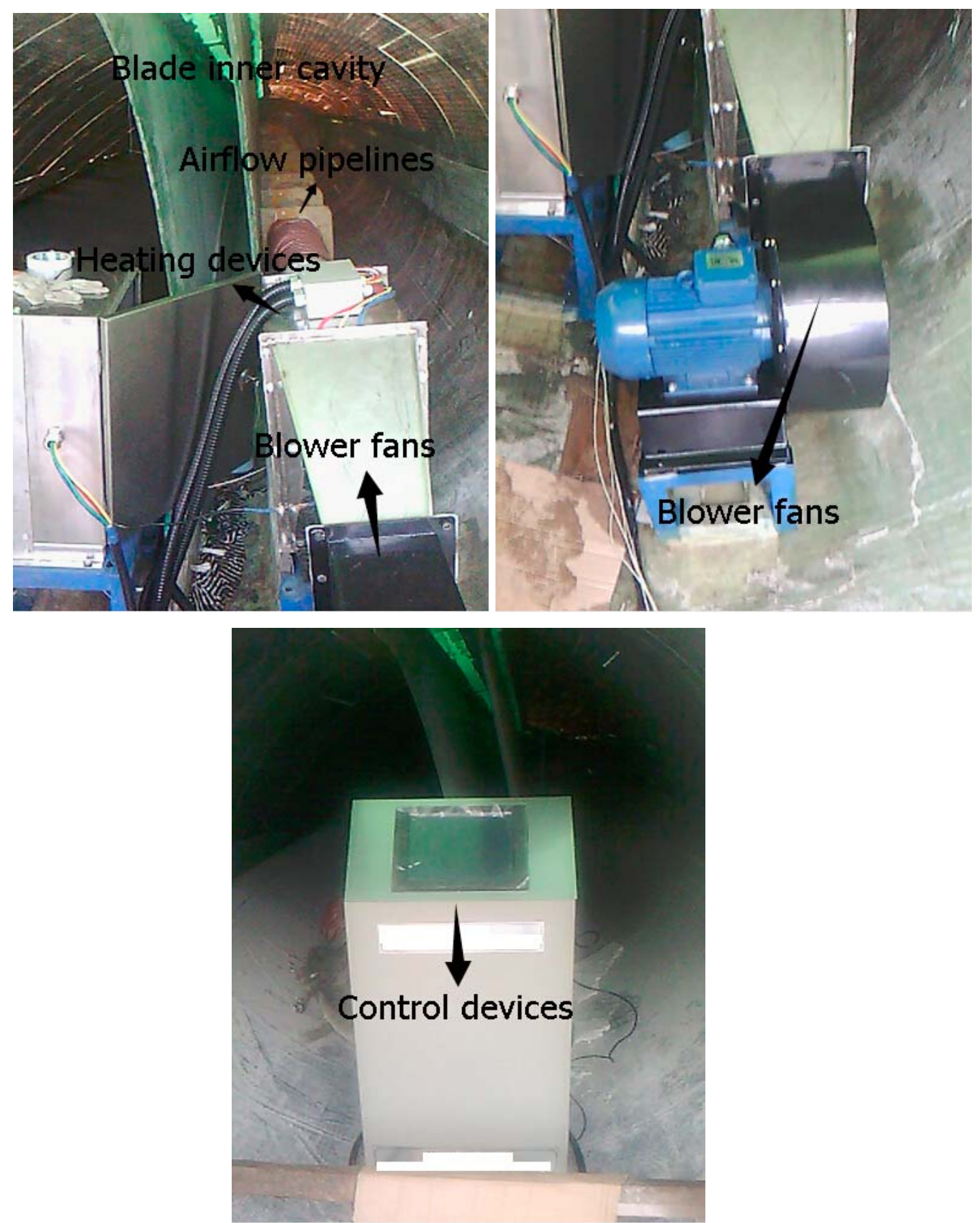

Fig. (5). Anti-icing system of the wind turbine blade.

and airflow pipelines are all placed in the inner cavity of the blade, the control devices are placed outside the blade. When the hot air anti-icing system is turned on, hot air blows to the leading edge of the blade inner cavity through airflow pipelines, then the hot air flows to the blade tip and then back to the blade root section through the cavity between two webs and trailing edge of blade of the cavity. In this way, it forms a loop to keep heating the blade.

\subsection{Measurement and Results}

Thermocouple 1 was placed near the leading edge parting line on the inner surface of the blade. Thermocouple 2 was placed 10 meters away from the blade root section near the leading edge parting line on the outer surface of the blade. In fact, the thermocouple 1 and 2 were placed at the same spot but different sides of the blade surface. Thermocouple 3 was placed in the air. The locations of the three thermocouples are shown in Fig. (6). Thermocouple 1 was used to measure the temperature of the blade inner surface (the temperature load for computation). Thermocouple 2 was used to measure the temperature of blade outside surface (for comparison with the computation result). Thermocouple 3 was used to measure the ambient temperature.

To reflect the real working situation, the blade in the experiment was sealed at the root section. Through control de- 


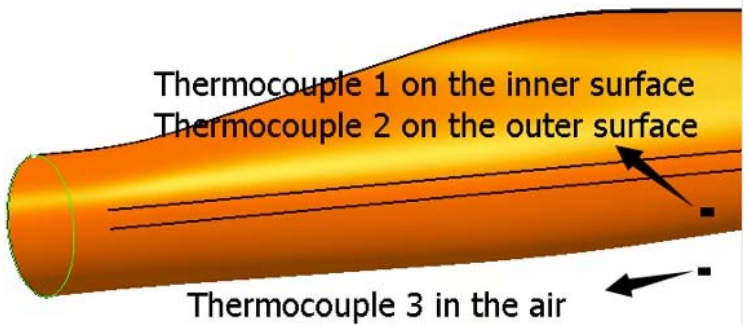

Fig. (6). Locations of thermocouples.

vices, it turned on the heating devices, blower fans and monitors the temperature data of each thermocouple. The data was collected every 60 seconds. When the temperature of thermocouple 1 reaches 50 Celsius degrees, control devices will automatically turn off all the devices.

The experimental result is shown in Fig. (7). It can be seen that as the experiment progressed, the temperature of the blade inner surface kept increasing. When the experiment began, there was a rapid increase. Following that, the slope of the temperature rise gradually decreased. During the whole process, the temperature of the blade surface kept increasing for deicing by transmission of the energy to the blade surface.

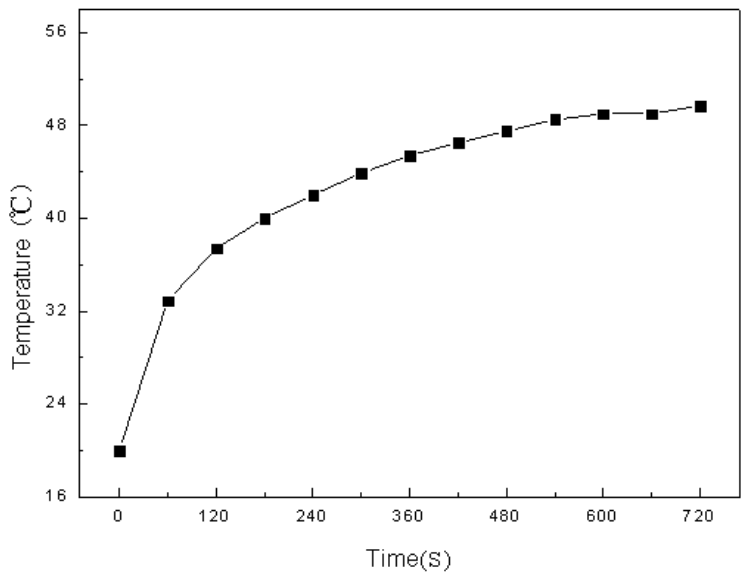

Fig. (7). Temperature curve of blade inner surface.

\section{FINITE ELEMENT SIMULATION OF WIND TURBINE BLADE TEMPERATURE FIELD}

\subsection{Finite Element Model of the Blade}

After verifying the feasibility of ply merging method, the temperature field of the actual wind turbine blade is considered. Here, a wind turbine blade of a specific model is selected for analysis. The solid model is built by FOCUS software with shell elements of certain ply information. After merging plies of the same material and glass fiber fabric of the same type in local areas, all the numbers of plies in the blade model are kept within 30 .

After ply merging and import of the model into Hypermesh, it cleans up the meshes of bad quality and defines the thermophysical parameters of each ply. Since in FOCUS only element assignment of the blade model is allowed, the element type must be switched here from SHELL181 to the desired SHELL131 in Hypermesh. After the element property settings of SHELL131, the final shell element model for ANSYS is obtained. The pre-processed model is shown in Fig. (8), among which each independent color region (component) represents a specific ply structure. Every component has a unique ply property corresponding to the SHELL131 element. The total number of elements for the model is about 36,000 .

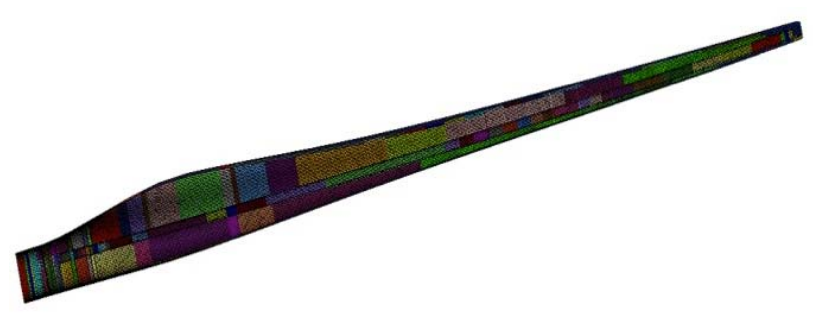

Fig. (8). Finite element model of the wind turbine blade.

\subsection{Load and Boundary Condition Setting}

The first type boundary condition is applied to the blade inner surface, which refers to the directly applied temperature load. Recall that the temperature load is measured through thermocouple 1 after turning on the anti-icing system as shown in Fig. (7). After importing the data of temperature load versus time with APDL command flow, the temperature load is applied to all the nodes on the blade inner surface.

The third type boundary condition is applied to the blade outer surface. Here, the convection between the blade outer surface and air is simplified as flow over cylinder. The heat transfer coefficient is calculated as $\mathrm{h}=12.5 \mathrm{~W} /\left(\mathrm{m} 2 \cdot{ }^{\circ} \mathrm{C}\right)$. In accordance with the experiment, the initial and ambient temperature are set as $25.3^{\circ} \mathrm{C}$.

\subsection{Simulation Results}

Based on the material parameters in Table $\mathbf{2}$ as well as other relevant load and boundary condition settings, ANSYS was used for the heat transfer analysis within 720 s after the anti-icing system was turned on. The simulated temperature field of the blade outer surface is shown in Fig. (10).

It can be seen from Fig. (9) that the outer surface of the blade tip is heated first. From the root to the tip section, there is a gradual temperature increase. Actually, there is a sharper temperature increase towards the tip at the leading edge than the trailing edge. The temperature increase is slower at the blade crossbeam and root section. In fact, it is the blade structure that determines the above temperature distribution: there are fewer and thinner plies from the blade root to the tip section. At the crossbeam section of the blade, there are more and thicker plies, leading to a less temperature increase at the crossbeam section [11]. Besides, there are two core material sections of Balsa and PVC foam material on both sides of the blade crossbeam. Due to the lower thermal conductivity of these core materials, the temperature increases at these areas are also quite gentle.

Comparison between the simulated and experimental temperature curve of thermocouple 2 (Thermocouple 2 is located 10 meters away from the blade root near the outer surface of the leading edge) can be seen from Fig. (10). 

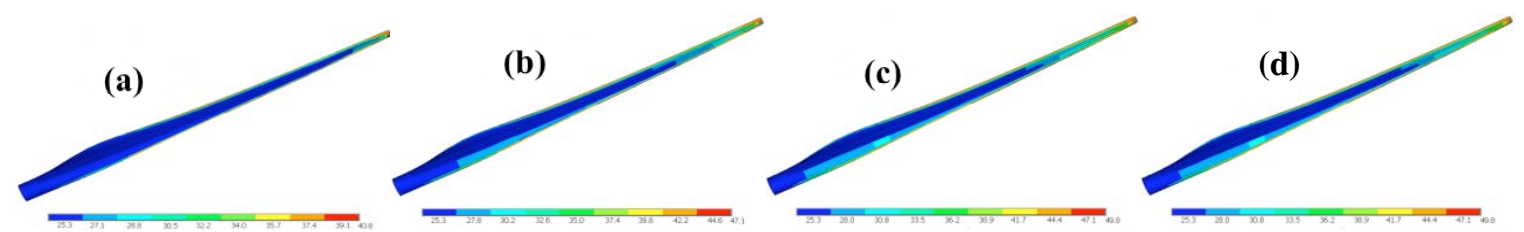

Fig. (9). Temperature field of outer surface at each time point, (a) 200s,

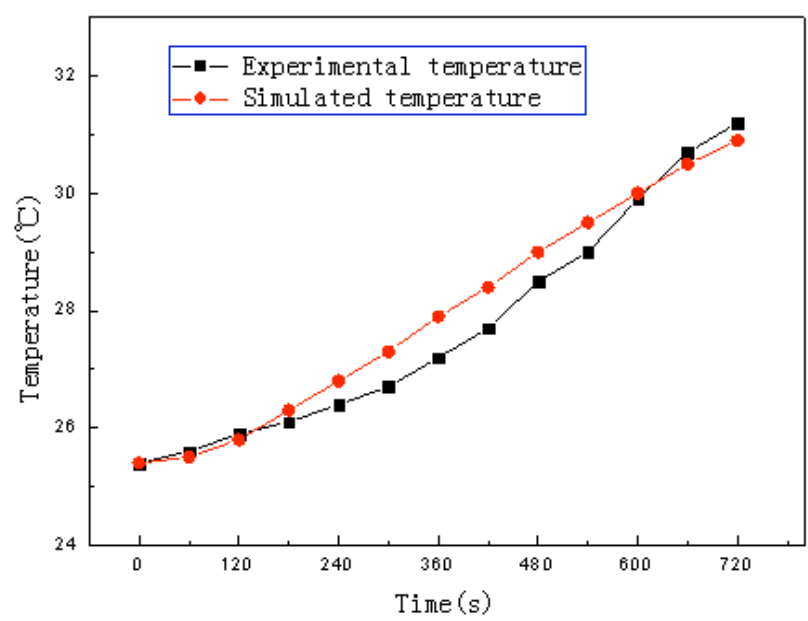

Fig. (10). Comparison between the simulated and experimental temperature.

From Fig. (10), it can be seen that both experimental and simulated temperature curves increase from the initial temperature, the difference between two curves is quite small in the first $120 \mathrm{~s}$. But after $120 \mathrm{~s}$, the simulation result is slightly higher than the experimental result, the main reason is due to impossibility to seal the gap between the thermocouple and blade. In this way, it leads to a potential thermal contact resistance [12], driving down the experimental temperature curve. However, after $600 \mathrm{~s}$, the gradually increasing ambient temperature in the experiment will increase the experimental result, which exceeds the simulation result. In summary, the difference between the experimental and simulation result is not more than 1 Celsius degrees (within 2.6\% for all data points), which shows good agreement between the two results. Therefore, it indicates the feasibility of applying SHELL131 elements in simulating the heat transfer process of wind turbine blade.

\section{CONCLUSION}

This article predicts the temperature field of wind turbine blades through simplification by ply merging method based on ANSYS SHELL131 shell elements. From the comparison between the experimental and simulation result, it is feasible to apply SHELL131 elements in predicting the temperature field of wind turbine blades. In this way, it provides reliable theoretical guidance for heat transfer analysis of wind turbine blades and research on anti-icing device optimization. (b) 400s, (c) 600s, (d) 720s.

The article is aimed to discover a new method for predicting temperature field of wind turbine blades by simplification of the models, boundary conditions, loads etc. For more accurate simulation result, it should consider more factor in practice, such as the dependence of material parameters on temperature, the uneven temperature distribution of blade inner surface, heat transfer with the outside air, potential icing etc.

\section{CONFLICT OF INTEREST}

The authors confirm that this article content has no conflicts of interest.

\section{ACKNOWLEDGEMENTS}

This work was supported by the New Strategic Industry (Energy) Investment Projects of National Development and Reform Commission (No. [2013]1029).

\section{REFERENCES}

[1] B. B. Hou, "Technology of large-scale anti-icing blades for low wind speed wind turbine," Converter Technology \& Electric Traction, vol. 3, pp. 78-81, 2013.

[2] B. G. Liu, and H. L. Wen, "Current status and prospect of word wind power," Energy Engineering, vol. 4, pp: 12-14, 2000.

[3] A. Noor, and K. L. Tenek, "Steady-state nonlinear heat transfer in multilayer composite panel," The American Society of Civil Engineers, vol. 118, no. 8, pp. 1661-1678, 1992.

[4] J. Argyris, L. Tenek, and F. Oberg, "A multilayer composite triangular element for steady state conduction/convection/radiation heat transfer in complex shells," Computer Methods in Applied Mechanics and Engineering, vol. 120, pp. 271-301, 1995.

[5] E. Peltola, M. Marjaniemi, "An ice prevention system for the wind turbine blades,". Proceedings of the European Wind Energy Conference, pp. 1034-1037, 1999.

[6] C. Jonsson, "Further development of Enercon'S de-icing system," Skellefte: ENERCON, 2010.

[7] Y. E. Ma, and Q. Sun, "3D-Degenerated shell element for heat transfer analysis in shallow composite laminates," Mechanical Strength, vol. 28, no. 5, pp: 708-711, 2006.

[8] ANSYS Company. ANSYS 12.1 User Manuals.

[9] W. Q. Tao, Heat Transfer, Northwestern Polytechnical University Press: Xi'an, 2006

[10] X. S. Yi, S. Y. Du, L. T. Zhang, Handbook of Composite, Chemical Industry Press: Beijing, 2009.

[11] J. T. Jin, and Z. P. Zhou, "The structure design of large-scale horizontal axis wind turbine blade," Renewable Energy Resources, vol. 27, no. 2, pp. 65-68, 2009.

[12] P. Zhang, Y. M. Xuan, and Q. Li, "Development on thermal contact resistance," CIESC Journal, vol. 63, no. 2, pp. 335-334, 2012. 